\section{NERUDA Y LOS ESCRITORES AMERICANOS EN CABALLO VERDE para la poesía}

\author{
TRINIDAD BARRERA
}

\begin{abstract}
Trinidad Barrera
Catedrática de literatura hispanoamericana de la Universidad de Sevilla. Su actividad crítica se ha centrado en la narrativa y en la poesía contemporánea. Ha sido profesora visitante en universidades europeas, latinoamericanas y norteamericanas. En narrativa es la autora de La estructura de Abaddón el exterminador, De fantasías y galanteos (Estudios sobre Adolfo Bioy Casares) y de ediciones de José Eustasio Rivera y Bioy Casares; en poesía ha trabajado autores desde León de Mera hasta Baldomero Fernández Moreno y con especial atención los movimientos de vanguardia hispanoamericanos. En literatura colonial, ha editado los Naufragios de Cabeza de Vaca, la Primera parte del Parnaso Antártico, de Diego Mexía, y estudiado, entre otros a Colón, fray Gaspar de Carvajal y Bernardo de Balbuena. Es autora también de la Letteratura hispano-americana y Del Centro a los Márgenes. Narrativa hispanoamericana del siglo $X X$.
\end{abstract}

Es bien conocido que la llegada de Neruda, desde Buenos Aires a España en el año $1934^{1}$, no pasó desapercibida. Su presencia ha sido comparada a la de Rubén Darío aunque entre la llegada del nicaragüense y ésta del chileno habían pasado por aquí Jorge Luis Borges, Oliverio Girondo y Vicente Huidobro, por citar sólo a tres de los grandes escritores del siglo XX. La intelectualidad española que Neruda conoció era muy distinta a la que vio Darío, además, en su caso, ya había habido algún que otro conocimiento previo de su obra, Rafael Alberti, según cuenta en sus memorias, había visto en 1930 su Residencia en la tierra.

No es ninguna novedad decir que Neruda estuvo muy vinculado a España. La guerra civil española sorprendió a Neruda en Madrid y precisamente la situación le servirá de inspiración para escribir España en el corazón, aunque ya hacía tiempo que España estaba en su corazón y siguió estándolo. Aquí en Madrid vería la luz en 1935 su segunda edición de $R e$ sidencia en la tierra gracias a Cruz y Raya. Sería la primera edición completa en relación con la primera, chilena, de 1933. La edición española es conocida como «Edición Cruz y Raya» porque las ediciones del Árbol dependían de la editora y revista de ese nombre dirigida por José Bergamín. A finales de mayo de 1934 Neruda llega a Barcelona, en calidad de cónsul de Chile, con la mirada puesta en Madrid a donde deseaba trasladarse; durante unos meses deberá oscilar entre las dos ciudades en espera del traslado. La llegada a Madrid es relatada por Sáenz de la Calzada quien cuenta que fue a esperarle a la estación del Norte en compañía de Federico García Lorca. En la capital encontrará también a Rafael Alberti. En el año 34 Lorca lo presenta como conferenciante en la Universidad Complutense de Madrid -pocos meses antes habían dado una conferencia al alimón en Buenos Aires. Sus palabras de presentación, cargadas de calidez y deferencia, fueron un espaldarazo para el poeta chileno y resultan sumamente significativas de la acogida que tuvo el poeta por parte de los jóvenes poetas del 27. Acogida que pocos meses después se concreta en el excepcional «Homenaje» que introduce la publicación separada de Tres cantos materiales, reflejo sin duda de la fraternidad y el reconocimiento que le rodea así como la atracción del modelo del intelectual de izquierdas encarnado en Alberti. Bergamín, Alberti, Rosales, Aleixandre, Guillén, Hernández o Lorca son algunos de los nombres que hay que asociar a su estancia en España por aquellos años que ha quedado ratificada también en su colaboración en las revistas españolas más importantes de entonces, Caballo Verde para la Poesía, El Mono azul, etc. Precisamente de la primera fue su director ${ }^{2}$.

En sus memorias, Confieso que he vivido, podemos encontrar mayores detalles de su paso por España pero parece indudable que fueron las vivencias de aquellos tumultuosos años, las que ejercieron en él un influjo decisivo para su abierta inclinación hacia el materialismo ideológico político ${ }^{3}$.
1

Había estado en Madrid uno cuantos días en 1927.

2

Juan Cano Ballesta, La poesía española entre pureza y revolución, Madrid, Siglo XXI, 1996.

3

Sobre su estancia madrileña, cfr. el reciente libro de Sergio Macías, El Madrid de Pablo Neruda, Madrid, Tabla rasa, 2004

Neruda y los escritores americanos en Caballo verde para la poesía TRINIDAD BARRERA 


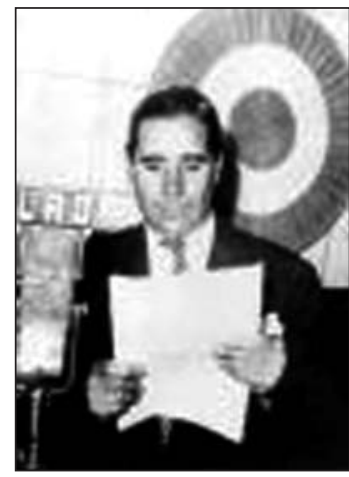

Raúl González Tuñón.

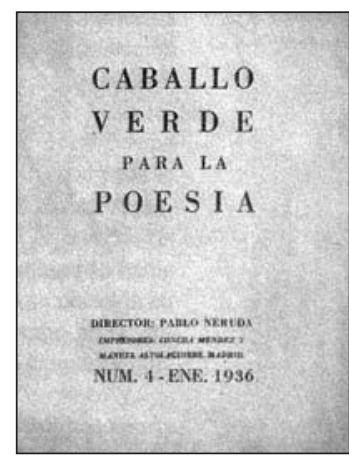

Portada. Caballo verde para la poesía.

\section{4}

Jan Lechner, «Introducción» a Caballo verde para la poesía. Reimpresión anastática de la edición de Madrid 1935/1936 Darmstadt, Kraus Reprint, 1974. En adelante $\mathrm{CV}$.

5

Juan Cano Ballesta, op.cit.; Antonio Jiménez Millán, «Sobre una poesía sin pureza. Notas acerca de Caballo verde para la poesía», Analecta Malacitana, 3 , 1980, pp. 243-260; José Manuel López de Abiada, «Notas sobre Caballo verde para la poesía», Cuadernos Hispanoamericanos, 430, 1986, pp. 141 163.; Sebastián de la Nuez, «La poesía de la revista Caballo verde de Neruda», Anales de Literatura Hispanoamericana, VI, 7, 1978, pp. 205-257.

6

Jan Lechner, op. cit., y Cano Ballesta, op. cit.

Neruda y los escritores americanos en Caballo verde para la poesía TRINIDAD BARRERA
El Caballo verde nerudiano es una revista plural que refleja, como dijo Lechner, gran parte del inquieto cielo literario de su tiempo ${ }^{4}$. Fueron cuatro números que vieron la luz entre octubre del 35 y enero del 36 , el siguiente, un número doble, estaba dedicado a Julio $\mathrm{He}-$ rrera y Reissig y ya terminado quedó en imprenta, paralizado por el estallido de la guerra civil. En noviembre del 36 Neruda abandona Madrid y se instala, tras un breve paso por Valencia, en Paris. En noviembre del 37 está ya en Chile.

Durante mucho tiempo la revista Caballo Verde para la poesía fue juzgada exclusivamente por las editoriales nerudianas, por esos cuatro prólogos de sus respectivos números, citados hasta la saciedad como signo del cambio de estética en la poética nerudiana. Hoy día estudios detenidos ${ }^{5}$ han puntualizado que ni fue una revista exclusivamente de poesía comprometida ni una amenaza abierta para la poesía pura sino, como dijo Neruda, «sin excluir deliberadamente nada, sin aceptar deliberadamente nada». Sólo desde esa consideración puede entenderse la nómina de los colaboradores. Resulta interesante detenerse en los hispanoamericanos para verlos en relación con el poeta chileno y con la estética que marcan los respectivos poemas que entregan para Caballo verde.

Siete escritores hispanoamericanos suben a la grupa de su Caballo, cuatro argentinos, Raúl González Tuñón, Ricardo Molinari, José González Carbalho y Miguel Ángel Gómez, dos chilenos, Ángel Cruchaga Santa María y Luis Enrique Délano y un cubano, Félix Pita Rodríguez. La nómina no es pequeña, pues sólo son diez los escritores no españoles que publican allí, pero sí desigual. De los argentinos, Tuñón y Molinari han sido ratificados por la historia literaria como dos grandes figuras de la poesía argentina del siglo XX, menos fortuna han corrido las trayectorias de los otros dos. Incluso los dos primeros son poetas muy distintos entre sí, lo que pone de relieve algo que se ha señalado desde los primeros comentarios a Caballo, que no es una revista avocada directa y exclusivamente al compromiso aunque ejemplos haya en sus páginas ${ }^{6}$. Raúl González Tuñón (1905-1974) es desde luego ejemplo de ese compromiso. Muy amigo de Neruda quien lo cita repetidas veces en su correspondencia, en sus memorias y en sus poemas. En la «Carta a la Rubia» (la es- posa del escritor argentino Pablo Rojas Paz; Neruda,OC,V,1029-1031) de 19 de septiembre de 1934, antes de la aparición de la revista, Neruda le cuenta a Sara Tornú de Rojas Paz su traslado a Madrid como cónsul, su permuta con la Mistral, sus fiestas y entre noticias y añoranzas le pregunta, «¿se casó Raúl?». En su famoso y durante mucho tiempo oculto «Madrid» (1935), Neruda en medio de imprecaciones contra la falsedad y la envidia del mundo literario que le rodea lo recuerda en uno de sus versos como un valor auténtico: «González Tuñón lucha». Cuando muchos años después Neruda repasa la poesía argentina los nombres que afloran son José Pedroni, Ricardo Molinari, Raúl González Tuñón y Oliverio Girondo (Neruda,OC,IV,1013). Lo más probable es que conociera a Tuñón durante su estancia en Buenos Aires, a la que llegó como cónsul en 1933.

Además de la corriente afectiva que les unía, González Tuñón fue un enamorado de España y un defensor a ultranza de la República. Comenzó muy joven, en Buenos Aires, sus andanzas literarias, a los diecisiete publicaba en Caras y Caretas, luego lo haría en Crítica y temprano también comenzó a ponerse del lado de las injusticias participando activamente en la guerra del Chaco. Su andadura fue de la mano de las revistas más sintomáticas de la actualidad porteña, Inicial, Proa - de la que fue redactor- y la emblemática Martín Fierro.

Pese a esta inocultable vocación martinfierrista está considerado un escritor de Boedo y no de Florida pero es que por Martín Fierro pasaron todos. En esta última comenzó a colaborar muy pronto. Ya en el número 8-9 (1924) aparecen tres poemas de su primer libro El violín del Diablo que vería la luz en 1926. Desde entonces hasta el número 44-45 (1927) colabora asiduamente publicando sus poemas e incluso en este último número tercia en la famosa polémica de "El meridiano» en carta a Benjamín Jarnés donde ataca a España y a Madrid en términos muy lejanos a los que pocos años después despertaría esta tierra, su situación política y su pueblo con los que se solidarizó sinceramente:

España, por culpa de quienes no supieron salvarla a tiempo, cabe, con todo su glorioso ayer, en el féretro de una antigua frase Old Spain... Cuando yo decida partir iré a Nueva York antes que a Madrid (385) 
No fue así, tras su segundo libro, Miércoles de ceniza (1928), marcha a Europa gracias al dinero obtenido al ganar el Premio Municipal de Poesía y es París el destino elegido, allí contactará con el surrealismo que dejará su huella en el libro siguiente. Corría el año 1929. Su siguiente visita a Europa fue con motivo de su viaje de boda y eligió España adonde llega en 1935. La etapa que aquí interesa, considerada además como la más notable de su obra, es la que circula entre La calle del agujero en la media (1930) y La rosa blindada (1936).

Al llegar a Madrid se encuentra con varios hechos de cabal importancia para su toma de conciencia, la insurrección de los mineros asturianos de octubre del 34, pórtico de la guerra civil que premonitoriamente anuncia en el poema de Caballo. Los hechos exigen su respuesta. Junto a Pablo Neruda estuvo, como representante de la delegación argentina, en el I Congreso Internacional de escritores para la defensa de la cultura, celebrado en $\mathrm{Pa}$ rís en junio de 1935. Firma, junto a Neruda, Serrano Plaja y otros, un texto elogioso sobre la figura de Barbusse recién fallecido y sobre la importancia de dicho Congreso («Los escritores y el pueblo», octubre de 1935) justo por la misma fecha en que sale a la luz su poema en la revista nerudiana. El viaje a Paris de 1935-36 coincide con el comienzo de su actividad militante -se había afiliado al Partido Comunista en 1934- y con el inicio de la Guerra civil española. Volvió a España, al frente, como enviado especial del diario Crítica y estuvo en el Congreso Antifascista en 1937. Neruda en España en el corazón al recordar su casa de las flores invoca a los amigos y les dice: «Raúl, te acuerdas? / te acuerdas, Rafael? / Federico, te acuerdas...?»

Todos estos datos explican el tono que respira el «Poema caminando» (CV,I,17-18), en la línea de su Juancito Caminador -su alter ego-, flâneur comprometido con lo que ve en su deambular de lo que hace un inventario, las pertenencias de un mundo y sus injusticias, «grifos secos que suenan / la música del agua subterránea tan cerca.... pozos negros con peones ahogados». Un «hay» insistente recorre el largo caminar del hablante lírico que pasa de imágenes surrealistas del comienzo a claras y rotundas admoniciones:

Hay millonarios.

Se han visto marchas de hambre sobre [flamantes villas y de burgueses muertos vientres agujerados y filas de mineros fusilados

y judías violadas y suicidios y ahorcados. Hay caretas de gases, alarmas con incendio, amuebladas con crímenes, motines con

bombas, espías, microbios de servicio

\section{[auroras,}

[secreto,

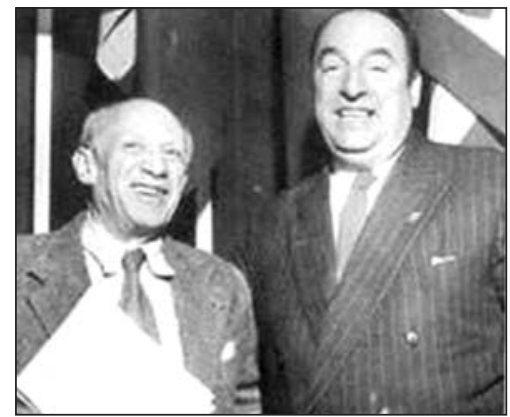

Con Picasso en París en 1949

7 Cano Ballesta, op. cit.
Hay bronca.

Hay la revuelta próxima que estallará de pronto como la luz tan súbita que inventa una ventana.

Hay posibilidades para la poesía.

Hay mañana.

En este poema está el poeta social, de corte profético, que se levanta contra la injusticia ya sea social o económica y contra todo tipo de discriminación. Los poemas revolucionarios escritos por esas fechas van a dar a su libro La rosa blindada (Homenaje a la insurrección de Asturias y otros poemas revolucionarios) (1936) que con Las puertas del fuego (1938) y La muerte en Madrid (1939) diseñan plenamente al poeta comprometido que es el que recoge Neruda en su revista, un poeta de total fidelidad con su ideario, acorde en esta ocasión a la cacareada "poesía sin pureza».

El poeta que supo blindar la rosa, supo por ende combinar estética y política, poesía como arma de combate, identificación entre los fines del arte y los fines de la revolución que se acomoda a las propuestas del surrealismo en su segundo manifiesto, movimiento con el que se sintió identificado. Si hemos de hacer caso a Cano Ballesta ${ }^{7}$, la poesía de Tuñón influyó en Miguel Hernández con quien le unía gran amistad, siendo para él un ejemplo, entre otros, que le encaminó hacia la poesía revolucionaria.

Para hacer honor al espíritu variado del Caballo nerudiano, la otra gran figura poética argentina elegida para el número 1 es Ricardo E. Molinari (1898-1996). Molinari, perteneciente también a la generación martinfierrista, es un poeta muy distinto a González Tuñón. Ambos fueron incluidos en la Exposición de la actual poesía argentina (1921-1927) de Pedro Juan Vignale y César Tiempo y ambos colaboraron en Martín Fierro, aunque antes Molinari, como González Tuñón, lo había hecho
Neruda y los escritores americanos en Caballo verde para la poesía TRINIDAD BARRERA 


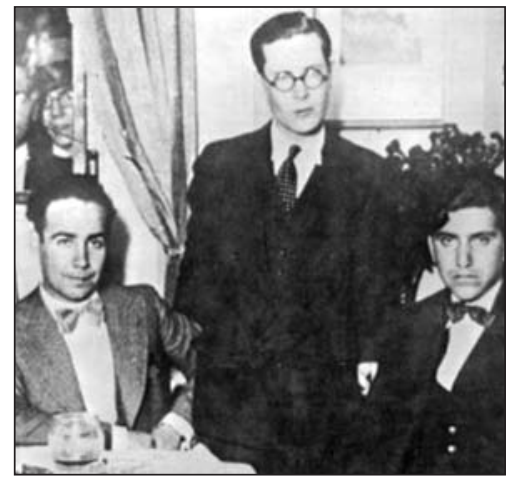

Leopoldo Marechal, Francisco Luis Bernárdez y Ricardo Molinari.

8

Luis Bagué Quílez «Introducción» a Ricardo E. Molinari, Mundos de la madrugada (1927-1991). Antología poética, Madrid, Huerga y Fierro, 2003. en Inicial (1923-1926). Molinari se incorpora a la gran revista ultraísta con posterioridad a Tuñón, concretamente en el número 39 , marzo del 27 , y prácticamente colabora en todos sus números hasta el final de la misma. Sus contribuciones ponen de relieve al poeta de El imaginero (1927), su primer libro, del que adelanta algunas composiciones, su pasión por Alfonso Reyes, por Góngora, o su implicación en la polémica del meridiano, en respuesta a Evar Méndez, donde se coloca del lado de su país rechazando el meridiano madrileño, en todo caso meridiano de «trastornos marroquíes» y de Primo de la «Costanera» (Martín Fierro, 42,4).

Desde los poemas de este primer libro se puede apreciar el particular lirismo de Molinari, una poesía

atenta a los ejemplos del romanticismo francés e inglés, que desconfía del culto a la novedad de muchos de sus camaradas y propende a la reflexión filosófica en detrimento de la imagen táctil o sensorial ${ }^{8}$.

Se puede decir que su poesía, de corte intimista, no es en absoluto una autobiografía sentimental aunque propende a la elegía, al ensimismamiento sin coordenadas espaciotemporales, lo que dificulta el rastreo biográfico a través de sus versos. La herencia española de la lírica del Siglo de Oro y de los cancioneros medievales halla eco en sus versos, un buen conjunto de libros, marcados por la introspección, que él mismo editó en sus primeros tiempos.

Estuvo en España en 1933 donde conoció a algunos miembros de la generación del 27 y otros poetas del momento, Alberti, Lorca, Altolaguirre, Moreno Villa, Gerardo Diego, etc. Probablemente Neruda lo conociese durante su estancia en Buenos Aires, en casa de Rojas Paz, y sin dudas, así lo dice, lo considera una de las tres o cuatro voces importantes de la poesía argentina. En la «Oda a Federico García Lorca» recuerda a sus amigos y lo cita junto a Oliverio, Norah, etc. Es el primero que publica en Caballo, junto a Tuñón. El poema que le envía a Neruda para su inserción es «Nao d'amores» que incluiría luego en sus Elegías de las altas torres (1937), con pequeñas variantes. El original de Caballo verde apare- ce desnudo, sin dedicatorias ni referencias de escritura. Al incluirlo en las Elegías está dedicado a Alfonso Reyes y termina con un paréntesis indicativo de fecha y lugar de escritura, Bahía de Río de Janeiro, 25 de abril de 1933.

Es un bello canto a un amor perdido, «porque tengo pegado en el pecho/ toda tu noche de pasión horrible», un amor clandestino, fugaz, precipitado, una «sombra de sueño», cargada de nostalgia que deja al poeta borracho de recuerdo:

(Si pudiera encontrarte. Si pudiera bajar a Río, esta noche;

andar por las calles oliendo las hojas gruesas de los árboles;

abandonarme en la tierra hasta llenarme

de piojos. Distraído)

Unos «piojos» que se suavizan en la versión posterior y se convierten en "piedad», lo que vela intencionadamente el texto hurtándole un contexto referencial mucho más explícito con la palabra «piojos». «Una poesía... oliente a orina y a azucena... donde la entrada en la profundidad de las cosas es un acto de arrebatado amor», diría Neruda en su primer prólogo, el del número 1, el que acoge los versos de Molinari bajo su divisa. Aquí no haya ningún atisbo de poeta social, sino llanamente el poeta íntimo, melancólico, de «gastado sentimentalismo», diría Neruda, cargado de humanidad, intentando exorcizar los recuerdos de un amor marcado por la imposibilidad. Un lirismo el suyo de «intenso temblor romántico», como lo califica José Olivio Jiménez, que debió ser muy del gusto nerudiano.

Fue bibliófilo y cuidó al máximo la publicación de sus libros, muchos de ellos ediciones del autor y algunos en plaquettes, y el mismo Lorca ilustró su poemario El tabernáculo (1934).

En el número 4, enero del 36, aparecen otros dos poetas argentinos, José González Carbalho (1900-1957) y Miguel Ángel Gómez (1911-1959). De ambos podríamos decir que son poetas olvidados, más aún el segundo, quizás la historia literaria los ha encasillado como menores, además, Gómez, en el momento de publicar en la revista nerudiana, era muy joven, tendría 23 años, estaba pues comenzando y no eran los casos de los anteriores.
Neruda y los escritores americanos en Caballo verde para la poesía TRINIDAD BARRERA 
González Carbalho, sin embargo, pertenecía a la misma generación de Tuñón o Molinari, murió relativamente joven y en su haber tiene unos once libros no siempre bien valorados por la crítica -es demoledora la que le hace Gullo en Martín Fierro a su obra El libro de Ángel Luis. Muy amigo de Rojas Paz al que prologó una antología, Neruda debió conocerle en casa de éste. Como poeta independiente de los cenáculos del ultraísmo lo considera Anderson Imbert; Ghiano, en su Poesía argentina del siglo $X X(1957)^{9}$, le dedica tres páginas y lo incluye, como Molinari o Tuñón, en el apartado «Imaginismo y formas de contención (1925-1940)» aunque su valoración final no es muy halagüeña, pues termina por decir que «la preocupación creadora de González Carbalho no se alcanza totalmente en su poesía por una insistencia simbólica que concluye en retórica».

Una visión elegíaca del mundo mueve parte de sus versos y en esa línea se inserta el poema que Neruda le publica, «La muerte verdadera». Neruda pregunta por él en la "Carta a la Rubia» ya citada y probablemente lo conociese, como al resto de los argentinos amigos, durante su estancia bonaerense. No tenemos mayores datos de esa relación, aunque lo encontramos citado en el Canto General, en el XII, «Los ríos del canto» (III: «A González Carbalho en Río de la Plata») (Neruda, OC, IV,378), sin embargo no lo cita en su artículo «La literatura argentina» donde sí cita a Molinari y a Tuñón.

El poema que aquí se publica no alcanza la calidad de los anteriores comentados, algunas imágenes afortunadas «Agua inicial en la primera lluvia/ del mundo...» se deslizan al lado de otras tópicas, «Río que une los tiempos y el espacio». Hay algo al menos que justifica su inserción, el carácter premonitorio de sus versos en la antesala de tiempo de muerte como si de un consuelo previo se tratara:

La muerte no es la rosa artificial,

$\mathrm{Ni}$ el agobiado luto de esa muerte

Incinerada, madre de los llantos.

Es algo más; es una edad del hombre.

González Carbalho es autor también de una antología muy conocida Índice de la poesía argentina contemporánea (1937). Menor fortuna ha corrido Miguel Ángel Gómez, incluido en la generación posterior a los cita- dos, la de 1940; Ghiano se limita a citarlo en un par de ocasiones sin entrar en ninguna consideración de su obra. Su primer libro, $\mathrm{La}$ rosa sobre los vientos es de 1934, después vendría Aurora (1941), Tierra melancólica (1943) con el que ganó el Premio Municipal, y Cancionero (1953). Murió asesinado en 1959. Su inserción en la revista nerudiana venía avalada con la reciente publicación de su primer libro. Gómez fue un gran animador de actividades poéticas y de revistas. Fundó el grupo «Canto» integrado entre otros por Enrique Molina, Olga Orozco, Daniel Devoto y J.R. Wilcock. Mantuvo una interesante relación epistolar con el poeta de Orihuela, Miguel Hernández, con el que llegó a intercambiar algunos poemas. Una carta del poeta de Orihuela al argentino cita a Tuñón y a Molinari con lo que se cierra el círculo de las amistades argentinas nerudianas. El que Neruda reproduce en Caballo verde lleva por título «Costa mortal» y está formado por tres tiempos que marcan el naufragio, en la línea residenciaria nerudiana, imbuido de un surrealismo particular:

Ramas del moho ya la sien orillas

En el polen desierto de sus poros

Donde su carne para flor es isla.

Párpado inútil, peso de su rostro.

Mar no esquivan, ni bocas, las corrientes

Arrojadas al valle de los ojos.

Surrealista es también el único poeta cubano que escribe en la revista, Félix Pita Rodríguez (1902-1990), poeta, narrador, ensayista, autor teatral, periodista, fue hombre de múltiples vertientes, activo colaborador de las principales revistas cubanas de las décadas del veinte y treinta, Revista de Avance, Social, Suplemento literario del Diario de la Marina. Visitó Paris en 1929 y, como Carpentier, estuvo en contacto con las principales figuras del surrealismo parisino. En compañía de Juan Marinello, Carpentier y Nicolás Guillén formó parte en 1937 de la delegación cubana al II Congreso de Intelectuales para la defensa de la Cultura que en plena guerra civil tuvo lugar en Valencia. Con anterioridad había estado en Europa, Italia en 1930, España en 1933. Entre 1938 y 1939 fue Jefe de redacción de $L a$ Voz de Madrid en la capital francesa. Fue desde el primer momento un poeta social, comprometido con la causa republicana

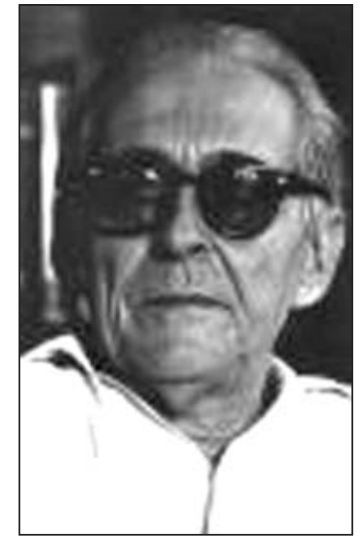

Félix Pita Rodríguez.

9

Juan Carlos Ghiano, Poesía argentina del siglo $X X$, MéxicoBuenos Aires, Fondo de Cultura Económica, Colección Tierra Firme, 65, 1957, p. 162.

Neruda y los escritores americanos en Caballo verde para la poesía TRINIDAD BARRERA 
española y años más tarde con la revolución castrista.

Neruda lo conoció en sus años de andanzas por Francia y España. El largo poema que aparece en el número 3 de Caballo no lleva título y se instala en la línea surrealista, muy al hilo de las Residencias nerudianas:

Abriendo manantiales donde la pulpa tierna
se pertenece en dobles, materiales extravíos.
Convenciendo grutas que oscilan y no pierden, de pie,
[sus infalibles profundidades,
pasando bajo agosto de llamas y lagartos
y flores amplias que ondulan su vivir enterrado.
Mixtificando fibras de cobre y algodones
aún de una tierra roja la ampulosa blancura.
Haciendo que semillas podridas no se obstinen,
invoquen leyes, nieguen
su anuencia para seguir ahondando en la rebusca;
tras el fragor, el clima, el titubeo de barreras de hormigas
que no saben si deben.

Fernández Retamar dejó dicho de él que quizás sea el único cubano surrealista ya que su poesía responde a la carencia de normas fijas de expresión, lo que lo convierte en un poeta cercano a esta escuela. Hasta 1948 no aparece su primer libro poético, Corcel de fuego. El cubano, como el argentino Gómez, en el momento de publicar en la revista nerudiana, son jóvenes promesas, casos muy distintos a los de Tuñón, Molinari o incluso González Carbalho que ya tenían libros en el mercado y eran poetas conocidos.

Cintio Vitier recoge a Pita Rodríguez en su Cincuenta años de poesía cubana (1901-1952) aunque se podría decir que ha gozado de mayor popularidad como prosista.

La nómina chilena remite a dos figuras muy desiguales, una de ellas es Luis Enrique Délano (1907), escritor, periodista y funcionario del consulado chileno en Madrid. A la llegada de Neruda a la capital, del que fuera secretario, contaba ya con una obra extensa. Su papel en la historia literaria no ha sido precisamente como poeta sino más bien como novelista o autor de biografías noveladas de personajes políticos como Balmaceda. En esta ocasión, Neruda le publica en el número 2 una «Oda a Lautreamont», de considerable extensión y dividida en tres partes, homenaje al autor de los «Cantos de Maldoror». No olvidemos que Lautréamont fue el gran ídolo del surrealismo. De nuevo la huella de las residencias nerudianas afloran por sus versos:

Con palmeras sin sombra, con pirámides viudas, Sobre el mar donde entonces saluda mi estatura, En el viento de arroz que reparte navajas, En un barco de noche, sin piedad, en la lluvia, Con los ojos ajenos al tiempo permanente

Y en los labios un ángel con un avión a cuestas Y bajo el gran paraguas que tormentas oculta, Y con definitivos clavos, con llaves negras, Con rosarios de nudos en la voz y en las manos Marchamos Maldoror, buendoror y fatiga.

Muy distinto es el otro chileno, el gran poeta Ángel Cruchaga Santa María (18931964) cuya obra surge al final del modernismo con algunas inquietudes prevanguardistas. Su primer libro es Las manos juntas (1915), después vinieron La selva prometida (1920), Job (1922), Los mástiles de oro (1923), La ciudad invisible (1928) y Afán del corazón (1933), todos ellos anteriores a la publicación en la revista de su amigo Neruda. Otros muchos libros completan su bagaje poético. Fue muy amigo de Neruda con el que llegó a compartir el amor de Albertina, y será Neruda quien le dedique una oda recogida en «Odas elementales» (Neruda,OC,II,85-86), le prologue algunos libros y mantenga con él frecuentes contactos, a veces a través de cartas. Cruchaga fue un poeta místico en cierto sentido, un poeta religioso con tonalidades bíblicas y evangélicas que derivan en un barroquismo expresivo. El dolor y la miseria del hombre con la fe en la esperanza es uno de sus grandes temas poéticos.

Su poesía evolucionó desde una religiosidad inicial, en diálogo con Dios y el universo, a poemas breves, herméticos de cerrado simbolismo y verso libre hasta llegar a partir de Paso de sombra (1939) a los problemas del pueblo, la tierra y la salvación de sus hermanos de raza y patria, es decir al poeta social.

El poema, incluido en él último número de la revista, lleva por título «Presencia del Sur» y está dedicado a la muerte, como el de González Carbalho. Es un sentido canto de invocación a la muerte como fiel compañera de la vida del hombre:

Y sin embargo, ahora que los años trepan la colina [del sueño

y amanece cerca de la ciudad de la vejez 
con tumbas y pájaros y soledades, eres una canción noble, como de hiedra en un blasón vetusto...

Ahora que el sol corrió su cortina de humo

y la tarde es el país de la tristeza,

acércame el amor, anticípame el perdido reino.

No deja de ser curiosa la constante alusión a la muerte, directa o indirectamente, en los poemas de estos siete poetas hispanoamericanos, parecieran preludiar los vientos negros que se avecinaban.

El saldo que arrojan estas publicaciones evidencian lo que decíamos al principio, por Caballo Verde desfilaron corrientes ideológi- cas y estéticas muy distintas y de este corpus analizado sólo tenemos un ejemplo de poesía militante, el de González Tuñón, todos los demás se mueven en un intimismo con diversos grados de reflexión, animismo o incluso diversos niveles de hermetismo surrealista. Desde luego sobresale un denominador común, el elemento corrosivo de las Residencias nerudianas que prácticamente se advierte en casi todos los hispanoamericanos si exceptuamos a Molinari y quizás Cruchaga Santa María. Si hubiera que señalar un denominador común por el que se igualan las colaboraciones de los poetas trasatlánticos ese sería el superrealismo. 